\title{
BEHAVIOR OF REINFORCED CONCRETE CONTINUOUS BEAMS STRENGHENED WITH NEAR SURFACE MOUNTED REINFORCEMENT
}

\author{
A. A. Khalil ${ }^{1}$, E. E. Etman ${ }^{2}$, A. H. El-Masry ${ }^{3}$ \\ ${ }^{1}$ Structural Engineering Department, President of Tanta University, Egypt. \\ E-mail:pressident@tanta.edu.eg \\ ${ }^{2}$ Structural Engineering Department, Dean of Faculty of Engineering, Tanta University, Egypt. \\ E-mail: emad.etman@f-eng.tanta.edu.eg \\ ${ }^{3}$ Structural Engineering Department, Researcher, Tanta University, Egypt.
}

\begin{abstract}
Using Near Surface Mounted (NSM) technique for flexural strengthening of reinforced concrete continuous beams became particularly attractive for researchers and applicators. Due to the existence of carbon fiber reinforced polymer (CFRP)laminates as external strengthening it is subjected to severe damage resulting from mechanical and environmental conditions. There is limited experimental work investigating the behavior of reinforced concrete continuous beams strengthened using NSM technique.This paper presents an experimental investigation of the behavior of reinforced concrete continuous beams strengthened with near surface mounted (NSM) technique in the hogging and sagging moment region. The main variable was changing the lengths of the NSM strips within the negative and positive moment region. The effect of the change in lengths of the NSM strips on the failure load, mid-span deflection, strain on reinforcement, slippage of CFRP strips and crack widths were investigated. The study revealed that the NSM technique can enhance crack and failure loads and controls crack widths.
\end{abstract}

Keywords: CFRP, NSM, continuous beams, sagging and hogging moments.

\section{Introduction}

Using NSM technique becomes particularly attractive for flexural strengthening in the negative moment regions of continuous beams. In addition, the existing of CFRP strips as an external strengthening could by subjected to severe damage due to mechanical and environmental conditions. After search there is limited experimental work on the behavior of strengthened RC continuous beams by NSM technique.

De Lorenzis and Nanni, 2001,[1] studied the behavior of R.C beam in shear strengthening with Near Surface Mounted fiber Reinforced Polymers Rods. It was concluded that in absence of steel stirrups capacity increased by $106 \%$, in case of steel stirrups below ACI recommendations capacity increased by $35 \%$ over the unstrengthened one. Hassan and Rizkalla, 2003,[2] perform Investigation of Bond in concrete structures strengthened with Near Surface Mounted Carbon Fiber reinforced polymer Strips. The main conclusion was that the use of near surface mounted CFRP strips is feasible and effective for strengthening/repair of concrete structures. De Lorenzis, et al., 2000,[3] studied bond of Near Surface Mounted FRP Rods in concrete masonry units. They concluded that the average bond strength was found to decrease as the bonded length increased. Yost, et al., 2004,[4] studied the behavior of Concrete Flexural Members strengthened with NSM CFRP Reinforcement. It was 
concluded that using deformed rods are more efficient than sandblasted rods in terms of bond beams with two different surface condition. they concluded that the ultimate load increased with increasing the bonded length of the rod but that effect may be versus in the sandblasted rods. De Lorenzis, et al., 2002,[6] prepare a modified pull-out test for bond of near-surface mounted FRP rods in concrete. performance. De Lorenzis and Nanni, 2002,[5] performed beam pull-out tests on simply supported The main conclusion was that The ultimate load increases as the bonded length increases, and also with the groove depth increasing. De Lorenzis and Nanni, 2001,[7] characterize FRP Rods as near surface mounted by making a Tensile test on FRP Rod, Bond test and shear test on a beam strengthened with FPP Rods by near-surface mounted technique. They concluded from all that tests that there is two bond failure modes were observed: splitting of the epoxy cover and cracking of the concrete surrounding the grove, depending on the groove size. R.El-Hache, et al., 2004,[8] studied Effectiveness of Near Surface Mounted FRP Reinforcement for flexural strengthening of reinforced concrete beams. The main Conclusion was the beams strengthened with NSM FRP Reinforcement achieved higher ultimate load than beams strengthened with externally bonded FRP reinforcement. De Lorenzis, et al., 2000,[9] discussed Strengthening of Reinforced Concrete Structures with near surface mounted FRP Rods by two types of tests (Bond test and Flexural test). A conclusion from that study is the strengthened ones showed an increase in capacity ranging from $25.7 \%$ to $44.3 \%$ over the control beam. Alkhrdaji and Nanni, 2000,[10] presents a demonstration strengthening project using FRP of a full-scale bridge for making a comparing between using external and near surface mounted strengthened system. They concluded that NSM technique is more effective than externally strengthened method using in decks and piers but in the last failure modes are closely related to the superstructure/substructure interaction and the pier boundary conditions. Cruz and Barros, 2004,[11] study a modeling of bond between near-surface mounted CFRP laminate strips and concrete. A research was developed to calibrate the parameters that define a local bond stress-slip relationship. Hassan and Rizkalla, 2002,[12] demonstrate many techniques for flexural strengthening of prestressed bridge slabs using FRP and the cost effect of every technique. The main conclusion of that search was that the use of Near Surface Mounted CFRP reinforcement is feasible and cost effective for strengthening prestressed concrete girders and slabs. Hassan and Rizkalla, 2004,[13] investigate the bond mechanism of Near-Surface-Mounted Fiber-Reinforced Polymer bars for flexural strengthening of concrete structures. They concluded that the maximum measured tensile stress in the CFRP bars at the onset of debonding was almost constant and ranged from 40 to $45 \%$ of the tensile strength of the bar, the average coefficients of friction between CFRP bars and adhesive of rough-and smooth-surface topographies were 0.66 and 0.33. Abdel-Hakim, A. K., 2004,[14] studied Flexural and Ductility Performance of RC Slabs Strengthened with NSM Reinforcement. The main conclusions were the use of NSM additional reinforcement led to normal ductile flexural failure mode, reducing the spacing between additional reinforcement increasing the failure load, slabs strengthened with NSM-CFRP reinforcement showed higher stiffness and generally less deflection up to failure than hose strengthened with externally. Khalifa, et al,1999,[15] presents an innovative anchoring system the external shear strength by embed a bent portion of the end (or near the end) of the FRP reinforcement into the concrete or masonry. They concluded that the U-wrap anchored to the flanges on both sides of the beam make the shear capacity in this specimen increased and no FRP debonding was observed at ultimate.

\section{RESEARCH SIGNIFICANCE}

This paper presents a study of the behavior of reinforced concrete continuous beams strengthened using Near Surface Mounted (NSM) technique. The main variable was changing the lengths of upper and lower CFRP strips. Failure load, load deflection behavior, CFRP strain, slippage of CFRP strip and crack widths were investigated in view of the effect of the change in the upper or lower CFRP strips. 


\section{TEST PROGRAM}

The test program included the testing of six - two spans - continuous beams. The concrete cross section of all beams was $120 \mathrm{~mm}$ in width and $250 \mathrm{~mm}$ in depth. The overall length of all beams was $4200 \mathrm{~mm}$ divided into two equal loaded spans of $2000 \mathrm{~mm}$. Reinforcement of all beams were similar; two $10 \mathrm{~mm}$ diameter bars were extended to cover the whole span in the positive moment region. To cover the negative moment, over the intermediate support, each beam was provided with two $12 \mathrm{~mm}$ diameter bars. Positive and negative reinforcement were made of 360/520 high tensile steel. For shear reinforcement; $8 \mathrm{~mm}$ diameter stirrups spaced at 200mm, made of 240/350 normal mild steel, were used to resist shear. Details of the tested beams are shown in Figure 1.

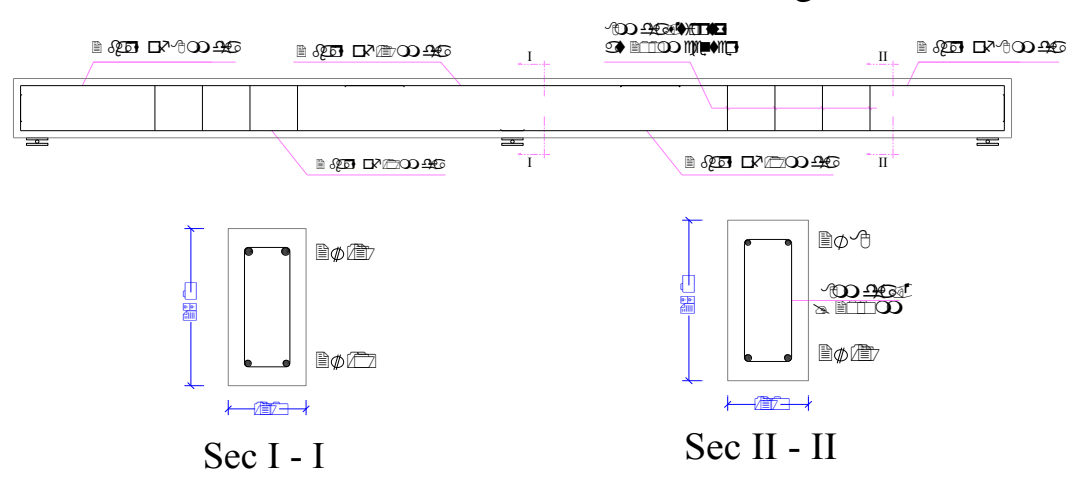

Figure 1. Details of reinforcement for different specimens

The tested beams were divided into two groups; the first group, G1, presents the strengthening of continuous beams through bonding different lengths of CFRP strips in the sagging moment region while the second one, G2, study the effect of changing of the length of the CFRP strips bonded on the hogging moment region.

\section{Strengthening Schemes and Test Setup}

To achieve the objectives of this research; the behavior of continuous reinforced concrete beams, strengthened in flexural using NSM technique by different lengths of upper and lower $1.2 \times 20 \mathrm{~mm}$ CFRP strip were investigated.

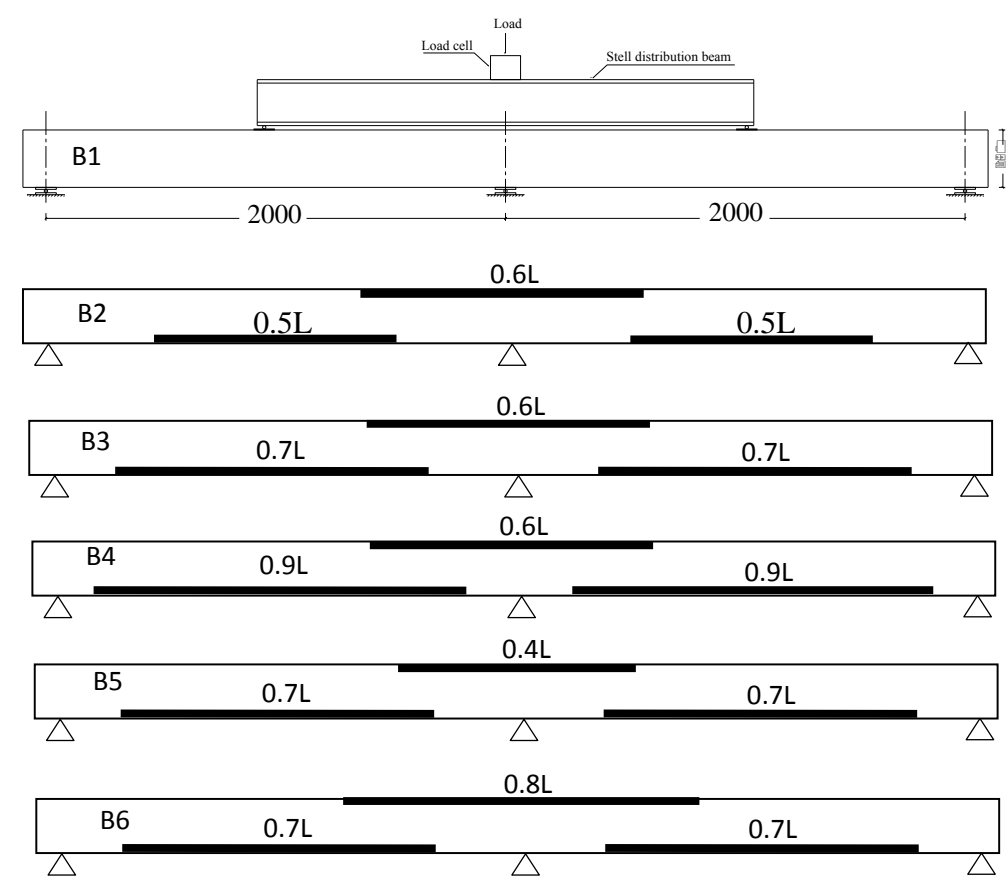

Figure 2. Schematic drawings of the tested beams . 
Figure 2 shows a schematic drawing of the tested beams. Beam B1 was tested without any strengthening which considered as a control beam. Changes of the lengths of the lower CFRP strip were investigated in beams B2, B3 and B4. The upper CFRP strip lengths were manifested in B3, B5 and B6. All beams have the same strip dimension and groove size. Full details and different strengthening configuration of the beams are shown in table 1.

Table 1 : Details of strengthening configuration of all specimens

\begin{tabular}{|c|c|c|c|}
\hline \multirow[b]{2}{*}{ Group No. } & \multirow[b]{2}{*}{ Beam } & \multicolumn{2}{|c|}{ Strengthening scheme } \\
\hline & & $\begin{array}{c}\text { CFRP plate in the } \\
\text { Sagging moment zone }\end{array}$ & $\begin{array}{c}\text { CFRP plate in the } \\
\text { Hogging moment zone }\end{array}$ \\
\hline \multirow{4}{*}{ G1 } & $\mathrm{B}_{1}$ & N/A & N/A \\
\hline & $\mathrm{B}_{2}$ & $\mathrm{~h} \times \mathrm{t} \times \mathrm{L}=20 \times 1.2 \times 1000$ & $\mathrm{~h} \times \mathrm{t} \times \mathrm{L}=20 \times 1.2 \times 1000$ \\
\hline & $\mathrm{B}_{3}$ & $\mathrm{~h} \times \mathrm{t} \times \mathrm{L}=20 \times 1.2 \times 1400$ & $\mathrm{~h} \times \mathrm{t} \times \mathrm{L}=20 \times 1.2 \times 1200$ \\
\hline & $\mathrm{B}_{4}$ & $\mathrm{~h} \times \mathrm{t} \times \mathrm{L}=20 \times 1.2 \times 1800$ & $\mathrm{~h} \times \mathrm{t} \times \mathrm{L}=20 \times 1.2 \times 1200$ \\
\hline \multirow{4}{*}{$\mathrm{G} 2$} & $\mathrm{~B}_{1}$ & N/A & N/A \\
\hline & $\mathrm{B}_{3}$ & $\mathrm{~h} \times \mathrm{t} \times \mathrm{L}=20 \times 1.2 \times 1400$ & $\mathrm{~h} \times \mathrm{t} \times \mathrm{L}=20 \times 1.2 \times 800$ \\
\hline & $\mathrm{B}_{5}$ & $\mathrm{~h} \times \mathrm{t} \times \mathrm{L}=20 \times 1.2 \times 1400$ & $\mathrm{~h} \times \mathrm{t} \times \mathrm{L}=20 \times 1.2 \times 1200$ \\
\hline & $\mathrm{B}_{6}$ & $\mathrm{~h} \times \mathrm{t} \times \mathrm{L}=20 \times 1.2 \times 1400$ & $\mathrm{~h} \times \mathrm{t} \times \mathrm{L}=20 \times 1.2 \times 1600$ \\
\hline
\end{tabular}

\section{INSTRUUMENTATIONS AND MEASUREMENTS}

Many types of instrumentation were used in this investigation. The use of dial gauge was dominant for deflection measurement by using one dial gauge at every mid span and used also for slippage gauging via using one dial gauge for every lower strip, CFRP strain determined by using strain gauge at the mid of upper \& lower strip. Demec points were fixed down the depth of the beam at positive and negative moment zones to help in the prediction of strain distribution along the depth. Figure 3 shows details of instrumentations fitted along the beam. The crack widths were measured at a level of the center line of upper and lower reinforcement, at different locations within the constant moment region using an illuminated microscope of $0.02 \mathrm{~mm}$ precision.

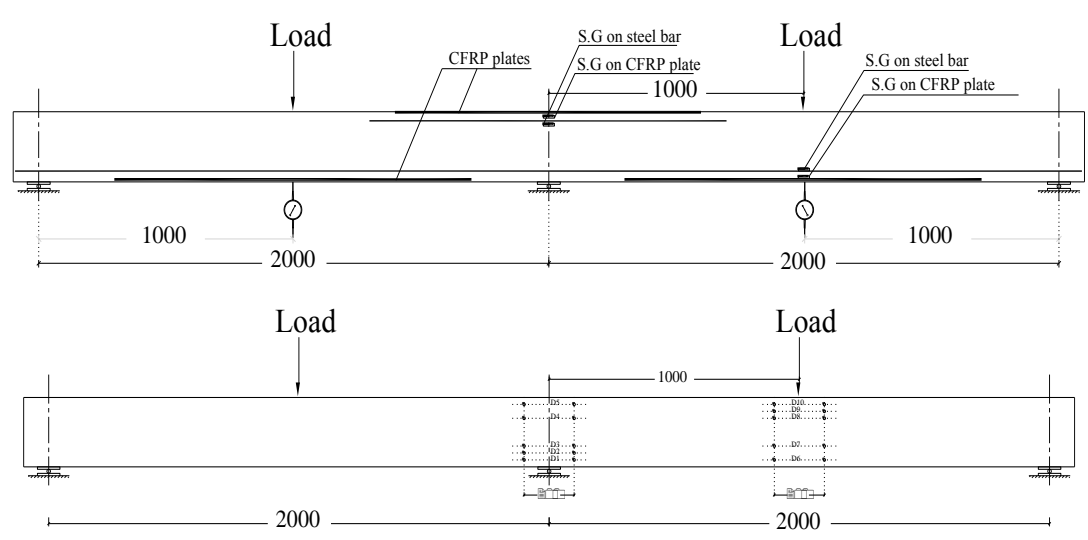

Figure 3. Details of Instrumentations 


\section{Properties' of concrete and strengthening materials.}

The beams were cast from concrete with characteristic compressive strength of about $28 \mathrm{MPa}$. The mechanical properties of the CFRP plates used as NSM strengthening and steel reinforcement propreties are shown in table 2.

Table 2 : Mechanical properties of CFRP material and steel.

\begin{tabular}{|c|c||c||c|c|}
\hline Material & $\begin{array}{c}\text { Dimension, } \\
\mathrm{mm}\end{array}$ & $\begin{array}{c}\text { Tensile strength, } \\
\mathrm{MPa}\end{array}$ & $\begin{array}{c}\text { Modulus of elasticity } \\
\text { E, MPa }\end{array}$ & $\begin{array}{c}\text { Elongation at } \\
\text { break\% }\end{array}$ \\
\hline \hline CFRP Plate & h.t $=20 \times 1.2$ & 2800 & $1.65 * 10^{5}$ & 1.70 \\
\hline \hline Steel & $\varnothing=8,10,12$ & $240 \& 360$ & $2.2^{*} 10^{5}$ & 1.50 \\
\hline
\end{tabular}

\section{Test results, presentation and discussion.}

\subsection{Load deflection}

Figure 4 shows deflection relations for the tested beams of groups G1 and G2. As shown in the figure; all strengthened beams recorded deflection values less than the control beam at the same load level. Group G1 showed that the increase in the length of the lower CFRP plate decreased the deflection and increased failure load. For group G2 the strengthened beams exhibited nearly the same first slope but with the increase in the bonded length of the upper NSM plate as in B6, the deflection decreased at the same load level. It could be noticed that the increase in the bonded length of either the lower or upper CFRP NSM strips would reduce the deflection values under the same load.

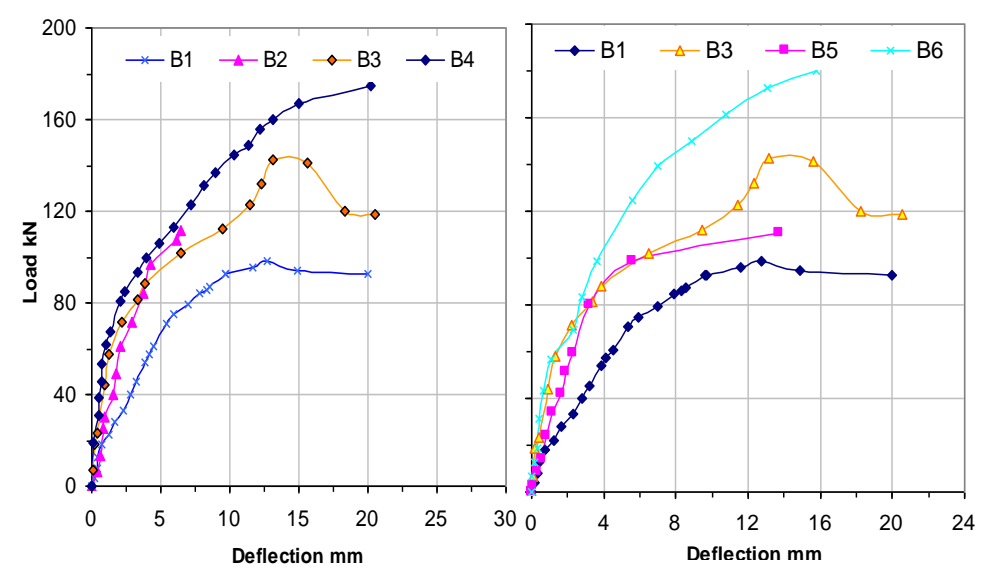

Figure 4. Load deflection relationships for G1 and G2

\subsection{Load strain relations of the lower CFRP plate}

This paragraph presents the effect of changing bonded length of either the lower or upper CFRP strips. For group G1, it may be seen that exceeding the bonded length of the CFRP plate from $1000 \mathrm{~mm}$ for B2 to $1400 \mathrm{~mm}$ for B3 increased the recorded CFRP strain by $57 \%$. While using CFRP strip length $1800 \mathrm{~mm}$ as in B4 raised the recorded strain by $72 \%$ above B2. On the other hand, group G2 did not show the same influence which appeared in G1. The maximum strain recorded on the lower CFRP plate of B3 did not exceed that of B5 which mean that increasing upper CFPR strip length by $33.3 \%$ did not show a noticeable effect on the strain of the lower CFRP strip. Quite the contrary, B6 which its upper CFRP strip length is double that of B5, the strain recorded for the lower CFRP strips exceeded that of B5 by about $14 \%$ which may reassure the conclusion that exceeding 
the length of the upper CFRP strip decreased the strain of lower CFRP strip. The load strain relations for the lower CFRP NSM plates are shown in Figure 5.
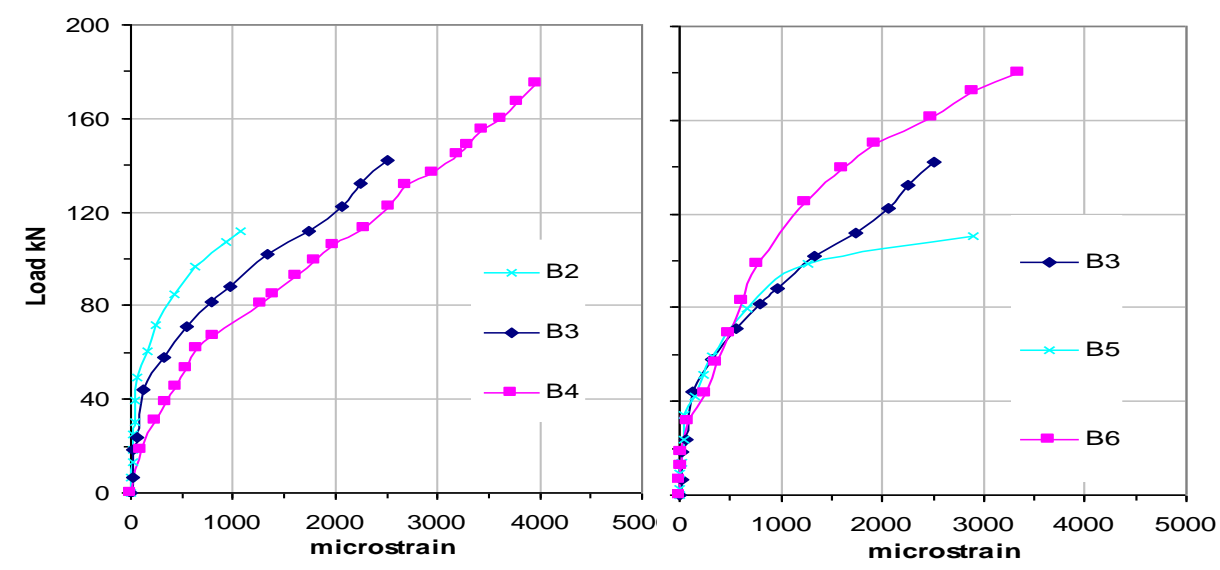

Figure 5. Load strain relationships for lower CFRP

\subsection{End slips response of NSM strengthening reinforcement}

The effect of change in the bonded length of lower NSM-CFRP plates in G1 is shown in Figure 6. From the figure it may be noted that increasing the bonded length of the lower CFRP strip from 50\% of the beam' span length in B2 to 70\% of the span length in specimen B3 delayed the beginning of the slippage for the NSM-CFRP strip. When exceeding the bonded length to $90 \%$ of the span length as in beam B4; no slippage was detected until failure.

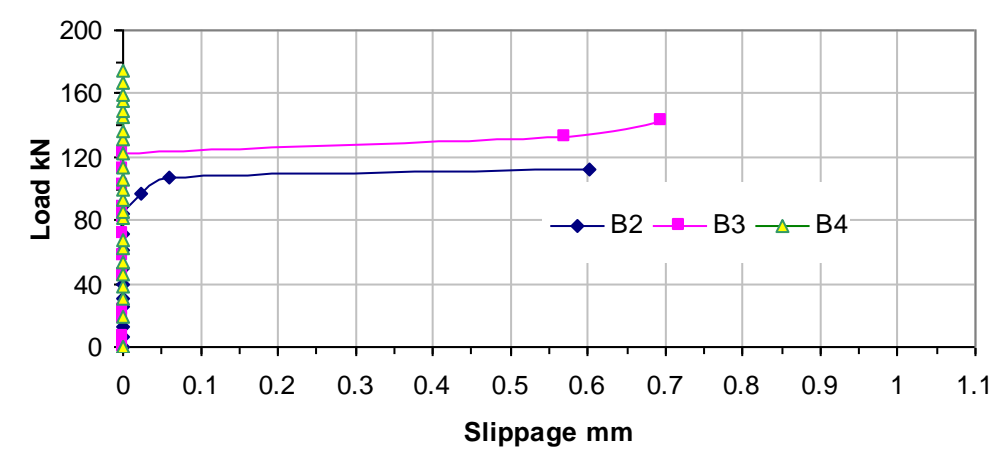

Figure 6. Load end slip relationships for lower NSM-CFRP strips for G1

The same trend was attained when increasing the bonded length of the upper NSM-CFRP plates as shown in figure 7.

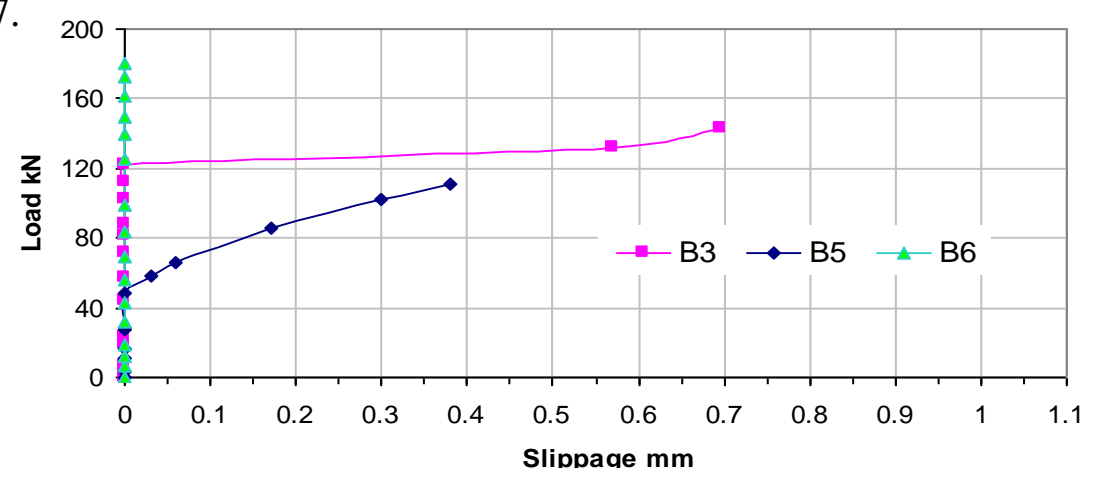

Figure 7. Load end slip relation for upper NSM-CFRP strip forG1

Specimen B5 strengthened with NSM-CFRP upper strip with bonded length 0.4 the span length exhibited early slippage than beam B3 with 0.6L NSM-CFRP upper bonded length. On the other 
hand, B6 which have 0.8L upper CFRP bonded length did not show any slippage until failure. It may be concluded that exceeding the bonded length of lower CFRP strip delayed its slip start.

\subsection{Ductility response}

The modulus of toughness, area under the load deflection curve, was used as a criterion for measuring ductility. The modulus of toughness represents the energy absorbed by the continuous beam up to failure. The failure is defined here as the load at which the deflection increases while the load is constant or decreasing. The calculated moduli of toughness for the different beams are listed in table 3 .

The main conclusion of the values showed in table 3 that the increasing of lower or upper bonded length of the NSM-CFRP strips increased the ductility of the beams. For example beams B2 and B3, showed $124 \%$ and $299 \%$ increase in ductility compared to control beam. The extra increase in ductility was manifested in beams B5 and B6 in which the moduli of toughness recorded increases of $266.8 \%$ and $316.7 \%$ over the control beam respectively.

It may be also noted that the increase in the bonded length of the lower NSM-CFRP strips by $28.5 \%$ increased the ductility by $60.8 \%$ while increasing the bonded length of the upper NSM-CFRP strips by $33.33 \%$ raised the ductility by only $16 \%$ which may mean that increasing the bonded length of the lower NSM strips may be considered as the main affecting factor on ductility

Table 3 : Modulus of toughness for tested beams

\begin{tabular}{|c|c||c|}
\hline Group & Beam & Modulus of toughness \\
\hline \hline \multirow{4}{*}{ G1 } & B1 & 33.37 \\
\cline { 2 - 3 } & B2 & 41.52 \\
\cline { 2 - 3 } & B3 & 106.05 \\
\hline & B4 & 75.83 \\
\hline \hline \multirow{2}{*}{ G2 } & B5 & 89.04 \\
\hline
\end{tabular}

\subsection{Failure modes}

Reinforced concrete beams strengthened using NSM-CFRP plates technique at sagging and hogging have been observed to fail in various modes, influenced by the bonded length. Flexural cracks initiated in tension sides at all beams, cracks propagated upwards with the increase in load. Final failures of the beams depended on the bonded length of upper or lower NSM-CFRP strips used

\subsubsection{Flexural shear failure}

Beams have this type of failure behaved in a ductile manner up to a level very close to failure, however due to the relatively short bonded length of the lower CFRP strip in B2, with the shortest sagging NSM-CFRP strip bonded length of $1000 \mathrm{~mm}$, the final failure was due to a major shear crack appeared at the cut-off end of the NSM-CFRP propagated dramatically towards the line of loading causing the final failure in shear. In specimen B5 that was strengthened at the hogging moment side with $800 \mathrm{~mm}$ bonded length of NSM-CFRP strips, it was noticed that flexural cracks started at tension sides of the beam. Crack propagation ended with a major crack at the end of upper CFRP 
strip then extended towards above the intermediate support then a sudden failure occurred. This sudden failure may be attributed to the concentration of stresses at the end of upper NSM-CFRP plate. Crack pattern and failure mode of B2 and B5 is shown in Figure 8.
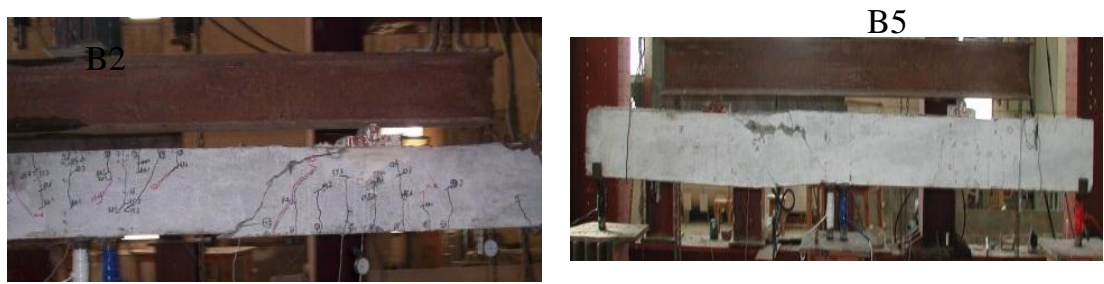

Figure 8. Flexural shear failure: Crack pattern at failure for B2 and B5

\subsubsection{Epoxy split failure}

In this type of failure, the specimens failed due to separation between epoxy adhesive and the CFRP strips. The beams that exhibited this type of failure showed sever hogging and sagging flexural cracks before failure. This type of failure was noted for beams B3 and B4 as shown in Figure 9.
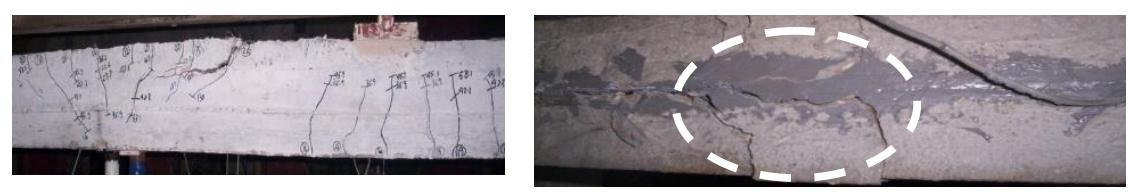

Figure 9. Epoxy split failure: Crack pattern at failure for B3 and B4

\subsubsection{Flexural failure}

This type of failure was characterized by the ductile manner of the specimen until failure. The flexural cracks propagated at both tension sides, sagging and hogging, and the final failure was due to crushing of concrete at compression side at intermediate support. This was depicted in beam B6 shown in figure 10.
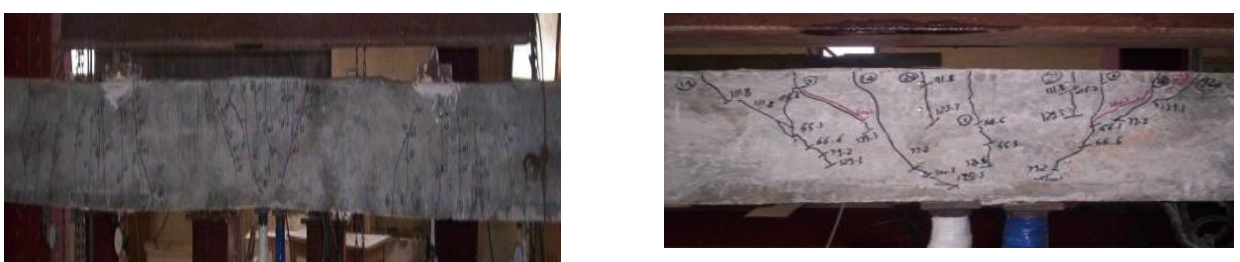

Figure 10. Flexural failure: Crack pattern at failure for B6

\subsection{Cracks Widths}

Cracks widths were measured for all specimens at $25 \mathrm{~mm}$ from upper and lower concrete faces. As shown in Figures 11; all strengthened beams showed widths of the sagging cracks that were less than those of the control beam at the same load level.

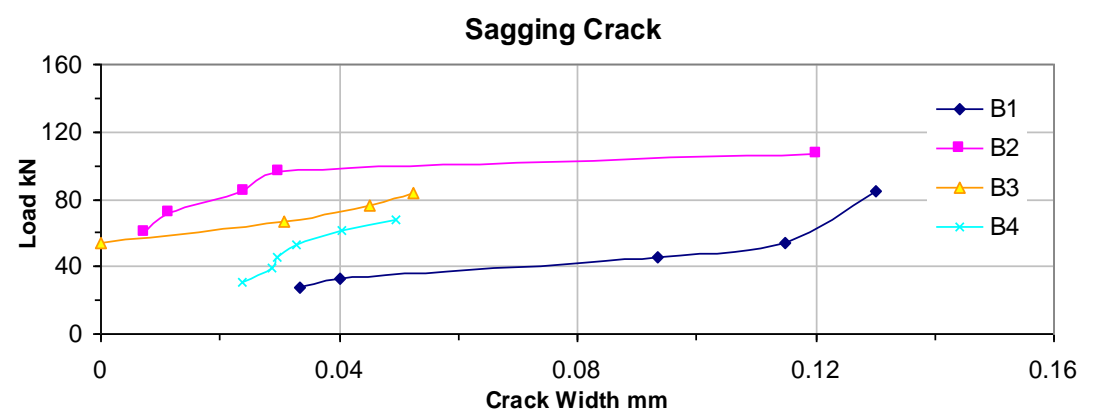




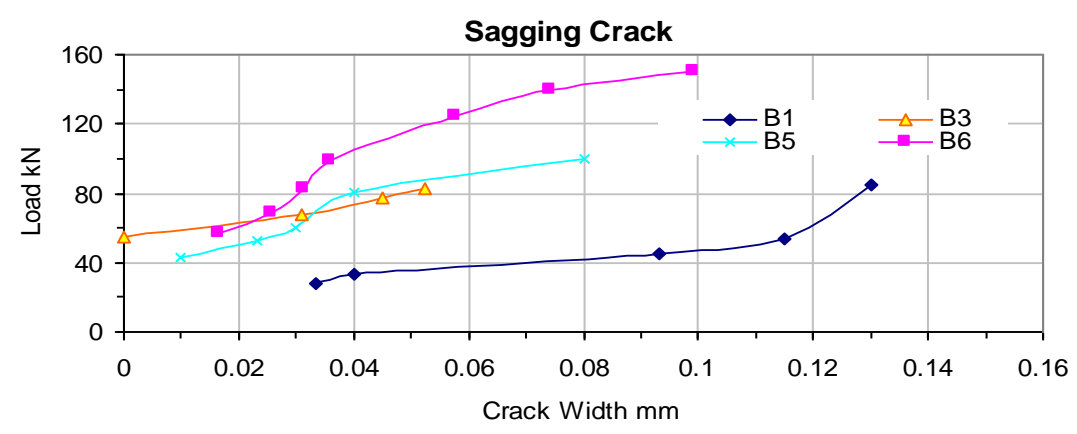

Figure 11. Crack width for G1 and G2 at mid span

It is clear that the widest crack width of the strengthened beams was recorded for B2, with the least lower CFRP strip bonded length. It can be concluded that increasing of lower CFRP strip bond length have a great effect at the crack width.

All strengthening beams at group G2 have the same lower CFRP strip length, so at the same load level B3 and B5 have nearly the same crack width where B5 which its upper CFRP strip length was less than B3 by $400 \mathrm{~mm}$ showed maximum recorded crack width that was bigger than B3. On the other hand; B6 lower crack width was less than B5 and B3 at the same load level. From those results it could be said that increasing of upper CFRP strip bonded length by more than $60 \%$ of the span length decreases the lower crack width.

Figure 12 shows the hogging crack widths over the intermediate support for group G1. All specimens in group G1 had the same upper NSM-CFRP strip bonded length of $1200 \mathrm{~mm}$ while the change was in the bonded length of the lower NSM-CFRP strips. Specimens B2 and B3 showed almost the same behavior of hogging crack width increase although beam B2 had lower NSM-CFRP strip bonded length of $1000 \mathrm{~mm}$. Beam B2 showed the widest crack compared to beam B3 that had lower NSMCFRP strip bonded length of $1400 \mathrm{~mm}$. Specimen B4 showed upper crack width bigger than all strengthened beams and less than control beam B1 which may be related to the high length of NSMCFRP strip at sagging which resulted in reduction of cracks widths at sagging side as shown in Figure 12 and formed an opposite additional tension at the upper cord which caused the widest cracks.

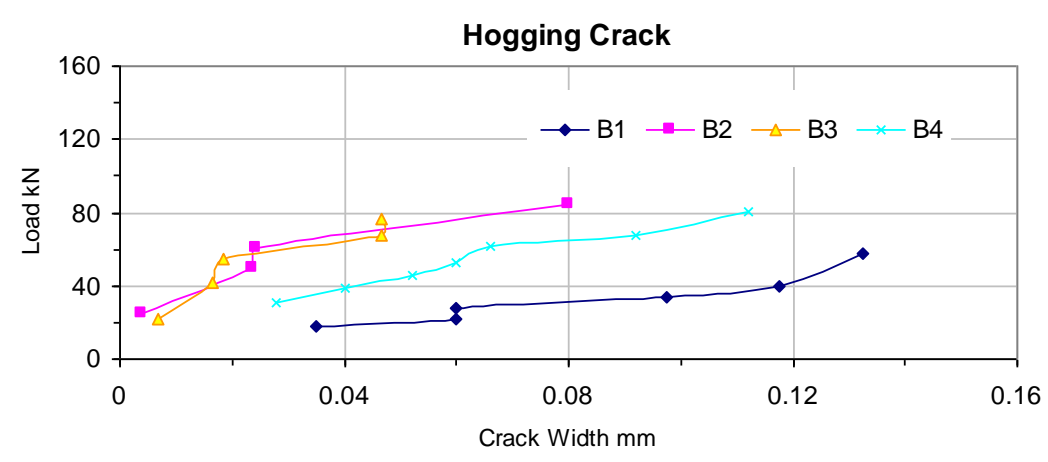

Figure 12. Hogging crack width for G1 over intermediate hinge

The hogging crack width of the group G2 is shown in Figure 13. the maximum crack width was recorded for B5, strengthened in the hogging moment region with NSM-CFRP strip having bonded length of $800 \mathrm{~mm}$, it may be also noticed that specimens B3 and B4 which they upper NSM-CFRP strip bonded length longer than B2 by $150 \%$ and $200 \%$ respectively, recorded crack width at the 
same load level of the maximum crack width of B5 that was less than that of B5 by 58.3\% and $52.5 \%$ respectively. It can be concluded that the increase of the bonded length of the NSM-CFRP strip within the hogging moment region decreases the crack widths.

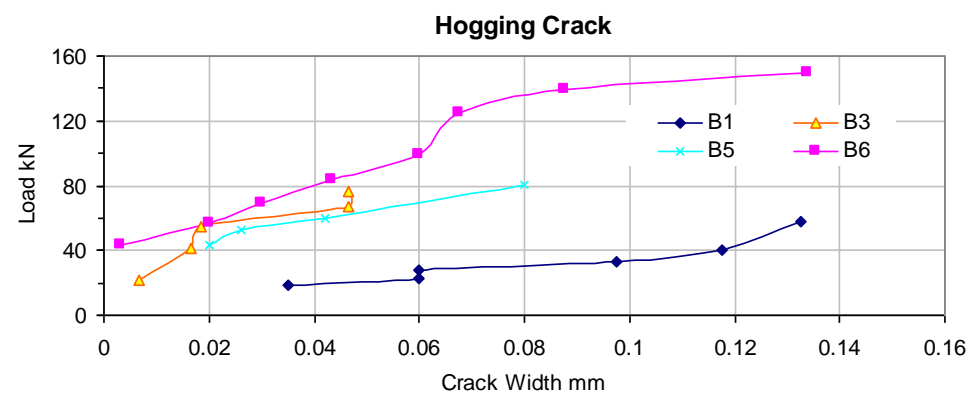

Figure 12. Hogging crack width for G2 over intermediate hinge

The following table shows the average sagging and hogging crack width and its number.

Table 4 : Number and crack width for all specimens

\begin{tabular}{|c|c|c|c|c|c|c|c|}
\hline ڤ్ & छ్ઁ & $\begin{array}{l}\text { Load } \\
(\mathrm{kN})\end{array}$ & $\begin{array}{c}\text { Average sagging } \\
\text { crack width }\end{array}$ & Load $(\mathrm{kN})$ & $\begin{array}{c}\text { Average hogging } \\
\text { crack width }\end{array}$ & 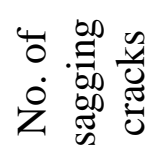 & 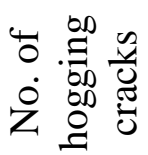 \\
\hline \multirow{4}{*}{$\bar{\mho}$} & B1 & 84.5 & 0.13 & 57.3 & 0.1325 & 10 & 7 \\
\hline & B2 & 107.22 & 0.12 & 84.56 & 0.08 & 15 & 9 \\
\hline & B3 & 88.2 & 0.0525 & 76.80 & 0.046 & 17 & 8 \\
\hline & B4 & 67.4 & 0.0495 & 80.90 & 0.112 & 18 & 8 \\
\hline \multirow{2}{*}{$\mathcal{O}$} & B5 & 100.0 & 0.08 & 81.00 & 0.08 & 8 & 5 \\
\hline & B6 & 149.8 & 0.099 & 149.80 & 0.133 & 18 & 8 \\
\hline
\end{tabular}

\subsection{Failure loads}

Figure 13 shows a comparison between crack and failure load of the strengthened beams for each group to clarify the effect of using different bonded lengths of the NSM-CFRP strips in the sagging and hogging moment regions for groups G1 and G2 respectively.
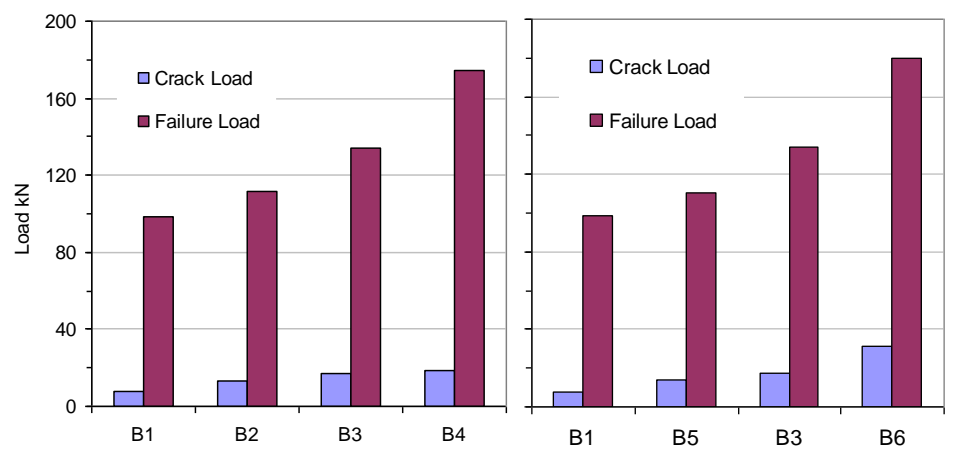
Figure 13 Comparison between crack and failure load

It can be concluded that the increase of NSM-CFRP strip' bonded length in either sagging or hogging moment region exhibited great contribution at increasing both crack and failure loads.

\section{Conclusions}

- The increase in the bonded length of the NSM-CFRP strip at sagging seems to decrease the deflection, in the same time leads to increasing strain at lower CFRP strip.

- The increase the bonded length of the Sagging NSM-CFRP strips lead to increase in crack and failure load and also decreased the crack width and delayed the slippage initiation.

- The increase in the hogging bonded length of the NSM-CFRP strip showed a slight effect at decreasing the deflection and also the crack load, in the same time lead to increasing strain at lower CFRP strip but shown clearly just at longer upper NSM-CFRP strips.

- Increase of hogging NSM-CFRP strip bonded length increased the failure load, decreased the crack width and delayed the slippage ignition.

- Using NSM-CFRP strip technique at hogging side, only, had a slight effect on failure load.

\section{References}

Abdel-Hakim, A. k., "Flexural and Ductility Performance of RC Slabs Strengthened with Near Surface Mounted Reinforcement,"AIN SHAMS UNIVERSITY, SCIENTIFIC BULLETIN vol. 39,No.3, September 30, 2004, PP.219-246.

Alkhrdaji, T.; and Nanni, A.,"Surface Bonded FRP Reinforcement for Strengthening/Repair of Structural Reinforced Concrete"Proc., ICRI-NRCC Workshop, Baltimore, MD, Oct. 30, 1999.

Cruz, J.S.; and Barros, J., "Modeling of Bond between Near-Surface Mounted CFRP Laminate Strips and Concrete,"ELSEVIER, Computers and Structures 82 (2004), PP. 1513-1521.

De Lorenzis, L.; Rizzo, A.; and La Tegola, A., "A modified Pull-out Test for Bond of Near-Surface mounted FRP rods in concrete,"ELSEVIER, Composites: Part B 33 (2002) PP.589-603.

De Lorenzis, L.; Rizzo, A.; and La Tegola, A., "Strengthening of Reinforced Concrete Structures with Near Surface Mounted FRP Rods,"International meeting on composite materials, PLAST 2000, Milan, Italy, May 9-11-2000.

De Lorenzis, L.; and Nanni, "Characterization of FRP Rods as Near-Surface Mounted Reinforcement,"JOURNAL OF Composites FOR CONSRUCTION / MAY 2001.

De Lorenzis, L.; and Nanni, A., "Bond between Near-Surface Mounted Fiber-Reinforced Polymer Rods and Concrete in Structural Strengthening"ACI STRUCTURAL JOURNAL, V99, No.2, March - April 2002 .PP123-132.

De Lorenzis, L.; Nanni, A.; and La Tegola, A., "Bond of Near Surface Mounted FRP Rods in Concrete Masonry Units,"The Seventh Annual International Conference on Composites Engineering (ICCE/7), Denver, Colorado, July 2-8,2000.

El-Hacha, R.; Filho,J.N.; Melo, G.S.; and Rizkalla, S.H, "Effectiveness of Near Surface Mounted FRP Reinforcement for Flexural Strengthening of Reinforced Concrete Beams"IV(ACMBS/MCAPC) Calgary, Alberta, July 20-23,2004/20-23 juillet 2004) 
Hassan, T.; and Rizkalla,S., "Investigation of Bond in Concrete Structures Strengthened with Near Surface Mounted Carbon Fiber Reinforced Polymer Strips,"JOURNAL OF COMPOSITES FOR CONSTRUCTION @ C ASCE / AUGUST 2003, PP248-257.

Hassan,T.;andRizkalla,S., "Bond Mechanism of Near-Surface-Mounted Fiber-Reinforced Polymer Bars for Flexural Strengthening of Concrete Structures"ACI Structural journal, V. 101,No. 6, November-December 2004, PP. 830-839.

Hassan,T.;andRizkalla,S., "Flexural Strengthening of Prestressed Bridge Slabs with FRP Systems,"PCI JOURNAL January - February 2002 , PP. 76-93.

Yost, J.R.; Gross, S.P and Dinehart, D.W., "Near Surface Mounted CFRP Reinforcement For The Structural Retrofit of Concrete Flexural Members,"IV(ACMBS/MCAPC) Calgary, Alberta, July 20-23,2004/20-23 juillet 2004. 